\title{
Modulatory Effects of $\alpha 1-, \alpha 2$-, and $\beta$-Receptor Agonists on Feline Spinal Interneurons with Monosynaptic Input from Group I Muscle Afferents
}

\author{
Ingela Hammar and Elzbieta Jankowska \\ Department of Physiology, Göteborg University, 40530 Göteborg, Sweden
}

Previous studies have shown that monoamines may modulate operation of spinal neuronal networks by depressing or facilitating responses of the involved neurons. Recently, activation of interneurons mediating reciprocal inhibition from muscle spindle (Ia) afferents and nonreciprocal inhibition from muscle spindle and tendon organ (Ia/Ib) afferents in the cat was found to be facilitated by noradrenaline (NA). However, which subclass membrane receptors are involved in mediating this facilitation was not established; the aim of the present experiments was to investigate this. Individual Ia- and Ia/Ib-inhibitory interneurons were identified in the cat lumbar spinal cord, and NA agonists were applied close to these neurons by ionophoresis. The agonists included the $\alpha 1$-receptor agonist phenylephrine, the $\alpha 2$-receptor agonists clonidine and tizanidine, and the $\beta$-receptor agonist isoproterenol. Effects were measured by comparing changes in the number of extracellularly recorded spike potentials evoked by electrical stimulation of muscle nerves and changes in the latency of these potentials before, during, and after application of the tested compounds. Results show that the facilitatory effect of phenylephrine is as strong as that of NA, whereas the facilitatory effect of isoproterenol is weaker. Clonidine depressed activity of both Ia- and Ia/Ib-inhibitory interneurons, whereas tizanidine had no effect. These findings lead to the conclusion that beneficial antispastic effects of clonidine and tizanidine in humans are unlikely to be associated with an enhancement of the actions of Ia- and $\mathrm{Ia} / \mathrm{Ib}$-inhibitory interneurons, and the findings also support previous proposals that these compounds exert their antispastic actions via effects on other neuronal populations.

Key words: spinal cord; spinal reflexes; cat; group I afferents; spasticity; noradrenaline; clonidine; tizanidine; phenylephrine; isoproterenol

\section{Introduction}

Interneurons with monosynaptic input from muscle spindle (Ia) and tendon organ (Ib) afferents play an important role in processing and forwarding information to $\alpha$-motoneurons. Modulation of their activity, therefore, must have a substantial impact on input to $\alpha$-motoneurons and, hence, on the subsequent motor output. Previous studies have shown that presynaptic inhibition mediated by GABAergic neurons may reduce greatly the input from group Ia muscle spindle and group Ib tendon organ afferents to spinal interneurons (Rudomin and Schmidt, 1999). In contrast, monoamines have been found to facilitate transmission between these afferents and interneurons, mediating Iareciprocal inhibition (Ia interneurons) and Ia and Ib nonreciprocal inhibition (Ia/Ib interneurons) (Jankowska et al., 2000). After damage to the descending tract cells releasing noradrenaline (NA) and serotonin (5-HT) and loss of monoaminergic facilitatory actions, weaker inhibition of $\alpha$-motoneurons by these interneurons might contribute, therefore, to the hyperexcitability of $\alpha$-motoneurons seen in spastic conditions (Pierrot Deseilligny, 1990; Delwaide, 1993). However, Ia-reciprocal inhibition was found to be reduced in only some spastic patients (Delwaide,

Received Aug. 12, 2002; revised 0ct. 3, 2002; accepted 0ct. 4, 2002.

This study was supported by grants from the National Institutes of Health (NS40863) and from the Göteborg Medical Society (I.H.). We gratefully acknowledge the expert technical assistance of Rauni Larsson.

Correspondence should be addressed to I. Hammar, Department of Physiology, Box 432, Göteborg University, 40530 Göteborg, Sweden. E-mail: Ingela.Hammar@physiol.gu.se.

Copyright $\odot 2002$ Society for Neuroscience $\quad 0270-6474 / 02 / 220332-07 \$ 15.00 / 0$
1993; Crone et al., 1994; Mazzocchio and Rossi, 1997; Morita et al., 2001), whereas in other patients it was found to be stronger (Yanagisawa and Tanaka, 1978; Hultborn and Malmsten, 1983b; Boorman et al., 1991) and to be either unchanged or more effective in cats after chronic spinal hemisection (Hultborn and Malmsten, 1983b). Spasticity, therefore, apparently is not always associated with a reduced inhibition from group I afferents. The reported enhancement of the inhibition by the $\alpha 2$-adrenoceptor agonists clonidine and tizanidine (Delwaide and Pennisi, 1994) nevertheless might explain the antispastic actions of these substances, provided clonidine and tizanidine have similar facilitatory actions on Ia and Ia/Ib interneurons as NA. If clonidine and tizanidine do not have such facilitatory actions, the $\alpha 2$ adrenoceptor agonists would be expected to reduce spasticity by acting on other neurons. The latter possibility has been indicated by observations that facilitation of transmission from group I afferents to a population of spinocerebellar tract neurons by NA is not associated with facilitatory actions of the $\alpha 2$-adrenoceptor agonists. On the contrary, local application of clonidine and tizanidine depressed rather than facilitated group I-evoked responses of these neurons (Hammar et al., 2002).

The aim of this study, therefore, was to compare the effects mediated by the $\alpha 2$-receptor agonists tizanidine and clonidine, the $\alpha 1$-receptor agonist phenylephrine, and the $\beta$-receptor agonist isoproterenol on interneurons mediating Ia-reciprocal and Ia/Ib-nonreciprocal inhibition of $\alpha$-motoneurons with the effects of NA. 
Ia interneurons

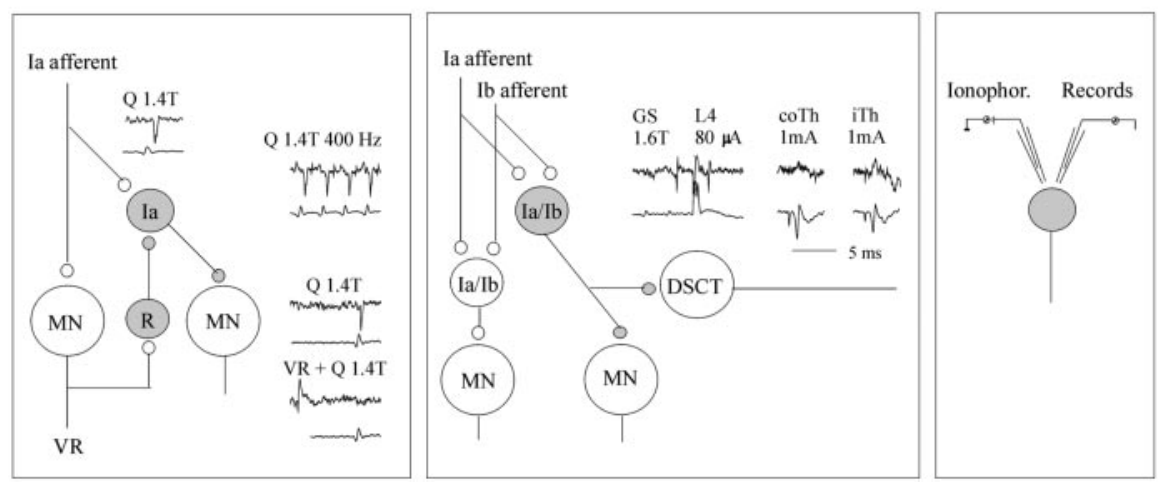

Figure 1. Experimental setup used for identification of interneurons and ionophoresis. Left, Diagram showing an interneuron mediating la-reciprocal inhibition (la, gray) and examples of records used for the identification of la interneurons: monosynaptic excitation from $\mathrm{Q}$, their ability to follow activation at $400 \mathrm{~Hz}$, and inhibition via Renshaw cells after stimulation of the L6 ventral root at intensities supramaximal for $\alpha$-motoneuronal axons. Middle, Diagram showing interneurons mediating la/lb excitation (white) and nonreciprocal inhibition ( gray) and records used to identify the inhibitory interneurons by antidromic activation from the L4 segment and lack of antidromic activation from the thoracic segments after stimulation up to $1 \mathrm{~mA}$ of either the ipsilateral (iTh) or contralateral (coTh) lateral funiculus. Right, The arrangement of the two micropipettes used for the ionophoresis (Ionophor.) and recording. They were attached to a double manipulator with separate microdrives. For details, see Jankowska et al. (1997, 2000). In this and the following figures, the top traces in each pair show microelectrode records (with the negativity down) and bottom traces show records from the cord dorsum and the time of arrival of the afferent volleys (with the negativity up). The time calibration in the middle panel is for records in both panels. MN, Motoneuron; $R$, Renshaw cell; DSCT, dorsal spinocerebellar tract neuron; $V R$, ventral root.

\section{Materials and Methods}

Preparation. All experiments were performed on deeply anesthetized cats following European Union and National Institutes of Health guidelines of animal care as well as the Swedish Animal Protection Act and Animal Protection Ordinance, and experiments were approved by a regional ethical committee of the Swedish National Board for Laboratory Animals. Data were obtained from five cats of both sexes weighing $2.6-3.5 \mathrm{~kg}$ and aged 6-9 months. Anesthesia was induced by a single dose of sodium pentobarbital ( $45 \mathrm{mg} / \mathrm{kg}$, i.p.) and maintained by intermittent doses of $\alpha$-chloralose (up to $60 \mathrm{mg} / \mathrm{kg}$, i.v.; Rhône-Poulenc, Santé, France) supplemented at regular intervals. The depth of anesthesia was monitored by regularly verifying the lack of withdrawal reflexes and the size of the pupils as well as by continuously recording blood pressure and heart rate. To maintain stable recording conditions, neuromuscular transmission was blocked with pancuronium bromide (Pavulon; Organon Teknika, Askim, Sweden; initially $0.4 \mathrm{mg}$ followed by $0.2 \mathrm{mg}$, i.v., every $2 \mathrm{hr}$ ) and artificially ventilated. End-tidal $\mathrm{CO}_{2}$ was measured and kept between 3.9 and $4.3 \%$ by adjusting the respiratory volume. Blood pressure was monitored via an intra-arterial catheter and maintained at $>100 \mathrm{mmHg}$. A buffer $\left(5 \mathrm{gm}\right.$ of glucose and $0.84 \mathrm{gm}$ of $\mathrm{NaHCO}_{3}$ in $100 \mathrm{ml}$ of distilled water) was infused at a rate of $1-2 \mathrm{ml} / \mathrm{hr}$, and urine was collected via an indwelling catheter.

Peripheral nerves in the left hindlimb were dissected, cut distally, and either threaded through subcutaneous cuff electrodes [quadriceps $(\mathrm{Q})$, sartorius] or mounted on pairs of silver wire electrodes in a paraffin pool [posterior biceps and semitendinosus (PBST), anterior biceps and semimembranosus (ABSM), gastrocnemius and soleus (GS), deep peroneal, plantaris $(\mathrm{Pl})$, sural, and superficial peroneal].

The spinal cord was exposed by laminectomy between the third and seventh lumbar segment (L3-L7) and at the level of the 12th and 13th thoracic segments (T12-T13). When ventral roots were stimulated, the dura mater was opened along the entire exposed spinal cord; however, in the remaining experiments it was kept intact, and only small openings were made to enable the insertion of the microelectrodes.

Recording and stimulation. Extracellular recordings from interneurons were made using glass micropipettes (tip diameter, $\sim 2 \mu \mathrm{m}$; resistance, $1.5-3 \mathrm{M} \Omega$ ) filled with $2 \mathrm{M} \mathrm{NaCl}$ solution. The cord dorsum potentials were recorded using a silver wire electrode placed on the surface of the spinal cord over the same segment, with the reference electrode in contact with a back muscle, allowing the segmental latencies of interneuronal responses to be determined with respect to the incoming volleys from group I muscle afferents.

Peripheral nerves were stimulated using constant-voltage rectangular pulses of $0.1 \mathrm{msec}$ duration. The stimulus intensity is expressed in multiples of stimulus threshold ( $T$ ) for the most sensitive fibers in a given nerve. The neurons were activated by submaximal stimuli, and the stimulus intensity was adjusted to evoke spike potentials in response to approximately one-half of a series of 20 stimuli. Single stimuli were used when possible. However, when single stimuli were ineffective, pairs of stimuli delivered $3.3 \mathrm{msec}$ apart were used, and the intensity was adjusted to evoke spike potentials in response to approximately one-half of the second stimuli. Extracellularly recorded spike potentials evoked at stimulus intensities of $<1.8 \mathrm{~T}$ for thinner nerves and up to $2.3 \mathrm{~T}$ for thicker nerves (Q) were considered to be evoked from group I afferents (Jack, 1978), and monosynaptic responses were defined as those evoked at a minimal segmental latency of $<1.1$ msec, considering that the segmental latencies of monosynaptically evoked EPSPs of group I origin are up to $0.7-0.8 \mathrm{msec}$ and that spike potentials of interneurons are delayed with respect to the onset of EPSPs by $\sim 0.2-0.3 \mathrm{msec}$ (Hongo et al., 1972). Ascending tract fibers were stimulated at the level of the T12 segment. The stimuli (constant current, $0.2 \mathrm{msec}, 0.5-1 \mathrm{~mA}$ ) were applied transdurally using pairs of electrodes placed over the left and right lateral funiculi.

Sample. Effects of the NA agonists were tested on a total of 24 Iainhibitory interneurons and $31 \mathrm{Ia} / \mathrm{Ib}$ interneurons. To differentiate between interneurons and ascending tract neurons, stimulation of the spinal cord at the level of T12, known to be rostral to the projection area of lumbar interneurons (Fern et al., 1988), was used. Failure to respond to stimuli supramaximal for activation of the ventral spinocerebellar tract (VSCT) fibers in a given experiment (usually activated at $<0.2 \mathrm{~mA}$ ) defined the neurons as lumbar interneurons. Interneurons mediating Ia-reciprocal inhibition (Ia interneurons) were searched for in the L5 and L6 segments. All neurons used for the analysis were activated from the Q nerve. They were identified by monosynaptic excitation from Q (at $<1.4 T$ ), the ability to discharge at $400 \mathrm{~Hz}$, and inhibition via Renshaw cells after stimulation of the L6 ventral root at intensities supramaximal for $\alpha$-motoneuronal axons (Hultborn et al., 1971a,b; Jankowska and Roberts, 1972) (see Fig. 1, left). Interneurons mediating nonreciprocal inhibition were searched for in the L6/L7 segments. Four such neurons were identified by monosynaptic excitation by group I afferents at $<1.7 \mathrm{~T}$ and by antidromic activation after stimulation of the ipsilateral lateral funiculus at the L4 segment using tungsten electrodes inserted to a depth of $1.5-2.5 \mathrm{~mm}$ in the area of the white matter through which axons of these interneurons are known to project (Hongo et al., 1983) (see Fig. 1, middle). The remaining intermediate zone interneurons were identified by their input from group Ia and Ib afferents (from Q, PBST, ABSM, GS, and $\mathrm{Pl}$ nerves), because a majority of such interneurons have been found previously to project to the L4 level, because interneurons mediating excitation from group I afferents were found to be located more caudally (McCrea, 1998), and because no differences have been found in the effects of monoamines within the population of these neurons. They will be referred to as Ia/Ib interneurons.

Ionophoresis. The investigated pharmacological agents were applied in the immediate area of the interneurons by ionophoresis. The recording and drug-containing micropipettes were attached to a double micromanipulator with two separate microdrives (Engberg et al., 1972) and, 
therefore, could be placed close to the tested neuron independently (Jankowska et al., 1997, 2000; Hammar et al., 2002) (see Fig. 1, right). This device allowed us to use only the recording pipette when tracking for interneurons (and to insert the drug-containing pipette into the spinal cord), placing it in a position close to the recording pipette (with the tips of the two pipettes 5-10 $\mu \mathrm{m}$ apart) just before starting the ionophoresis. A $10 \mathrm{nA}$ retaining current was used when the drug-containing pipette was advanced through the spinal cord. Two series of control records of interneuronal responses were taken before the ionophoresis began: the first control before the insertion of the drugcontaining pipette and the second control when this pipette had reached its position close to the recording pipette, but before ejecting the drug, to ensure that the placement of the micropipette did not have any mechanical effects on the neuron. The drugs were ejected by passing a negative current of $20 \mathrm{nA}$ for up to 3 min while simultaneously recording from the neuron through the recording micropipette. Changes in the resistance of the drug-containing pipette during the ionophoresis were monitored by continuously observing the shape and the amplitude of a current pulse. After completing the ionophoresis, the drug-containing pipette was withdrawn from the spinal cord, and the neurons were recorded from during a recovery period lasting up to $25 \mathrm{~min}$. The following compounds were used (in M): 0.2 tizanidine (Sandoz, Basel, Switzerland), 0.1 clonidine (Sigma, St. Louis, MO), 0.2 phenylephrine (Sigma), and 0.2 isoproterenol (Sigma). The compounds were dissolved in distilled water with the $\mathrm{pH}$ adjusted to 4.5 by adding $\mathrm{HCl}$. The drug-containing pipettes had a tip diameter of $\sim 2.5 \mu \mathrm{m}$ and a resistance of $12-20 \mathrm{M} \Omega$. We relied on previous control tests to exclude the possibility that any observed effects were attributable to the effects of $\mathrm{H}^{+}$ions rather than the ionophoresed compound (Bras et al., 1989) as well as on opposite effects of different drugs when the same ionophoresis procedures were used. When no effects were found, the compounds were tested on intermediate zone field potentials evoked from group II afferents known to be depressed by these compounds (Bras et al., 1989), to ensure that the solution was effective.

Analysis. The effects of ionophoresis were evaluated by comparing the number of spike potentials evoked by nerve stimulation with any changes in the latency before, during, and after ionophoresis. The comparison was made with potentials evoked before the insertion of the drugcontaining pipette (control 1) rather than with those after the placement of this pipette and directly preceding the ionophoresis (control 2), because of possible effects of diffusion of fast-acting drugs, despite the 10 $\mathrm{nA}$ retaining current. Responses to 20 consecutive stimuli were sampled every $15 \mathrm{sec}$ for as long as the ionophoresis continued and every $5 \mathrm{~min}$ thereafter during the recovery phase. Peristimulus time histograms and cumulative sums were created on-line and stored in parallel with the original data records using a software program designed for this purpose (Drs. Eide, Holmström, and Pihlgren, Göteborg University, Göteborg, Sweden; see Jankowska et al., 1997). Spike potentials evoked after either single stimuli or the first of a pair of stimuli were used for this purpose, even when the neurons originally responded only to the second stimulus. The reason for this was that when responses to the first stimuli appeared during application of monoamines, the refractory period after them precluded a reliable interpretation of responses to the second stimuli. To restrict the data to responses evoked by monosynaptic actions of group I afferents, these were sampled within time windows of $1 \mathrm{msec}$ (as measured from the earliest response at latencies compatible with a monosynaptic coupling, $0.8-1.1 \mathrm{msec}$ from the first positive peak of the afferent volley). Data are expressed as means \pm SEM. The statistical significance was calculated using Wilcoxon signed rank test.
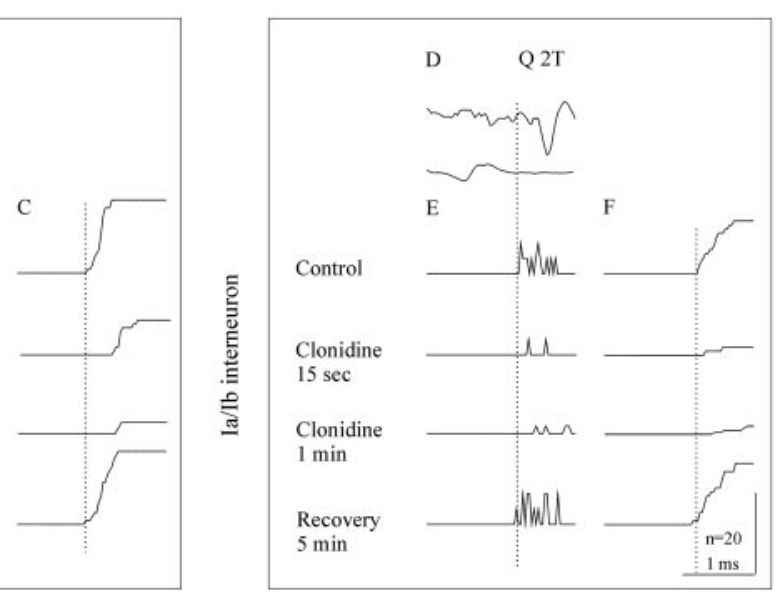
$\mathrm{ms}$

Figure 2. Examples of the depression of responses of an la interneuron $(A-C)$ and an la/lb interneuron ( $D-F)$ by clonidine. $A$, $D$, Control responses. $B, E$, Peristimulus time histograms aligned with the records in $A$ and $D$, respectively, showing responses fore, during, and after ionophoresis. $C, F$, Cumulative sums of the same responses. Note the decrease in the number of responses

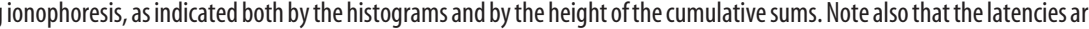
longer during ionophoresis than during the control and recovery periods. Dotted vertical lines indicate minimal latencies in the in $F$ applies to all records. Vertical scale bars are for $C$ and $F$

\section{Results}

The main results of this study are that the synaptic actions of group I afferents on Ia-inhibitory interneurons and Ia/Ibinhibitory interneurons are either depressed or unaffected by the $\alpha 2$-adrenoceptor agonists clonidine and tizanidine, whereas they are facilitated by the $\alpha 1$-adrenoceptor agonist phenylephrine and the $\beta$-adrenoceptor agonist isoproterenol.

\section{Effects of the $\alpha 2$-adrenoceptor agonists clonidine and tizanidine}

Clonidine

The effects of clonidine were investigated on five Ia interneurons and seven Ia/Ib interneurons. As illustrated in Figure 2 and summarized in Figure 4, clonidine depressed responses of both populations of interneurons. The depression was expressed primarily as a decrease in the number of responses evoked by a series of 20 stimuli. The latencies were modulated more variably and, although they were delayed in some neurons, no clear overall effects were found. For Ia interneurons, the mean number of responses decreased from $13.6 \pm 2.3$ to $7.4 \pm 3.4(p<0.05)$, and for $\mathrm{Ib}$ interneurons the mean number of responses decreased from $8.7 \pm 2.2$ to $4.1 \pm 1.9(p<0.05)$ after 2 min of ionophoresis. As shown in Figure 4, the depression of Ia interneurons appeared later but was more persistent than in Ia/Ib interneurons. In Ia interneurons, no significant decrease in the number of responses occurred until after $1 \mathrm{~min}$ of ionophoresis, and the recovery was seen only after $>5$ min after the termination of the ionophoresis. In contrast, depressive actions of clonidine on $\mathrm{Ia} / \mathrm{Ib}$ interneurons were usually seen already after $15-30 \mathrm{sec}$ of ionophoresis and the recovery was prompt, starting just after the ionophoresis was discontinued.

\section{Tizanidine}

The effects of tizanidine were investigated on nine Ia interneurons and $10 \mathrm{Ia} / \mathrm{Ib}$ interneurons. In none of these neurons were any consistent modulatory effects found during or after ionophoresis either in the number of responses or in the latencies. After 2 min of ionophoresis, the mean number of responses had increased from $11.3 \pm$ 2.5 to $12 \pm 2.6$ (not significant) in Ia interneurons, and it remained 


\section{Ia interneuron}
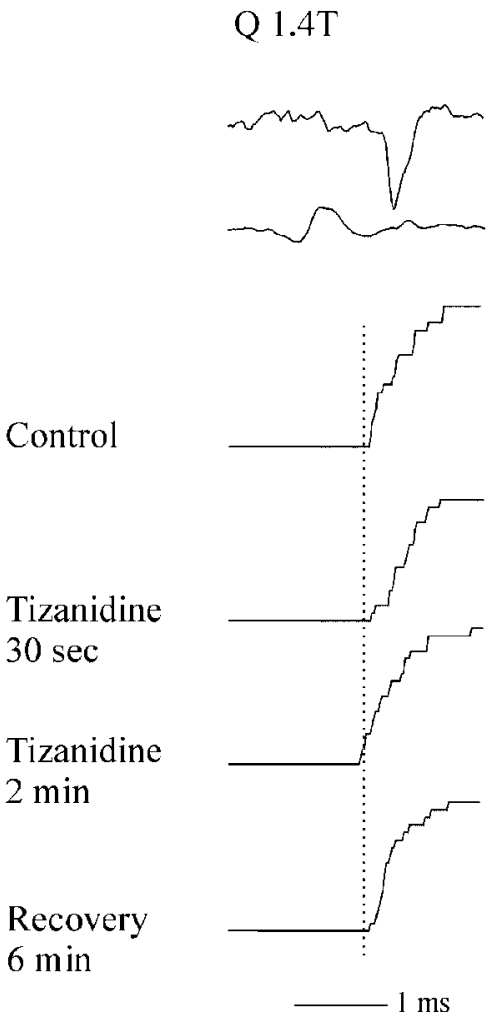

$\mathrm{Ia} / \mathrm{Ib}$ interneuron
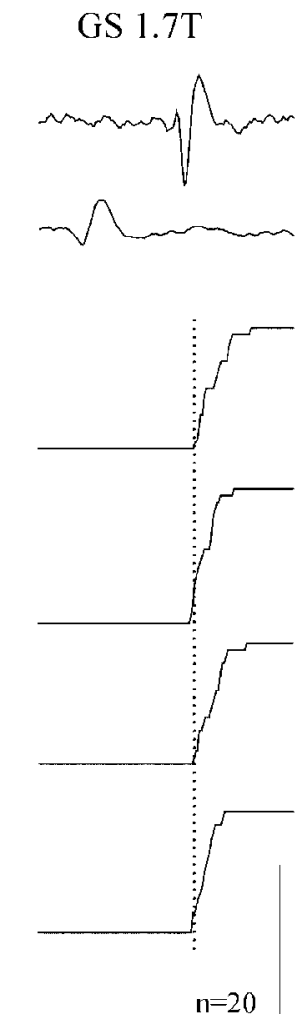

Figure 3. Examples of negligible effects of tizanidine on responses of an la interneuron (left) and an la/lb interneuron (right). Top, Neuronal responses to stimulation of the peripheral nerves and simultaneously obtained records of afferent volleys from cord dorsum. Bottom (and aligned with the neuronal responses), Cumulative sums showing responses before, during, and after the end of ionophoresis. Note that the number of responses remained practically unaffected during ionophoresis. The latencies also were practically unaffected, although, as illustrated on the left, shorter latencies were noted occasionally. Other indications are as in Figure 2.

unchanged $(11 \pm 1.49$ compared with $11 \pm 2.05$ after ionophoresis; not significant) in Ia/Ib interneurons. In four of the nine Ia interneurons, the ionophoresis was continued for an additional $1 \mathrm{~min}$, up to a total of $3 \mathrm{~min}$, resulting in a mean number of responses of $11.5 \pm$ 0.3. This lack of effect of tizanidine is illustrated in Figure 3 and summarized in Figure 4.

Effects of the $\alpha 1$-adrenoceptor agonist phenylephrine and the $\boldsymbol{\beta}$-adrenoceptor agonist isoproterenol

\section{Phenylephrine}

In contrast to the effects mediated by the $\alpha 2$-receptor agonists tizanidine and clonidine, the modulatory effects of the $\alpha 1$ receptor agonist phenylephrine were facilitatory on the two populations of investigated interneurons. In both Ia interneurons $(n=5)$ and $\mathrm{Ia} / \mathrm{Ib}$ interneurons $(n=8)$, the onset of facilitation was prompt and evident already after $15 \mathrm{sec}$ of ionophoresis, with the number of responses having increased from $5 \pm 1.3$ to $16.4 \pm$ $1.8(p<0.05)$ after $2 \mathrm{~min}$ of ionophoresis for Ia interneurons and from $9 \pm 1.76$ to $17.7 \pm 0.6(p<0.05)$ for Ia/Ib interneurons. The recovery was slow, and in several cases it was reflected primarily in a change in the slope of the histograms, as illustrated in Figure 5 (left), rather than in the total number of responses plotted in Figure 7. For the entire sample, the number of responses $10-15 \mathrm{~min}$ after ceasing ionophoresis remained significantly increased $[15 \pm 1.9(p<0.05)$ and $15.3 \pm 1.1(p<$
Ia interneurons

$\mathrm{Ia} / \mathrm{Ib}$ interneurons
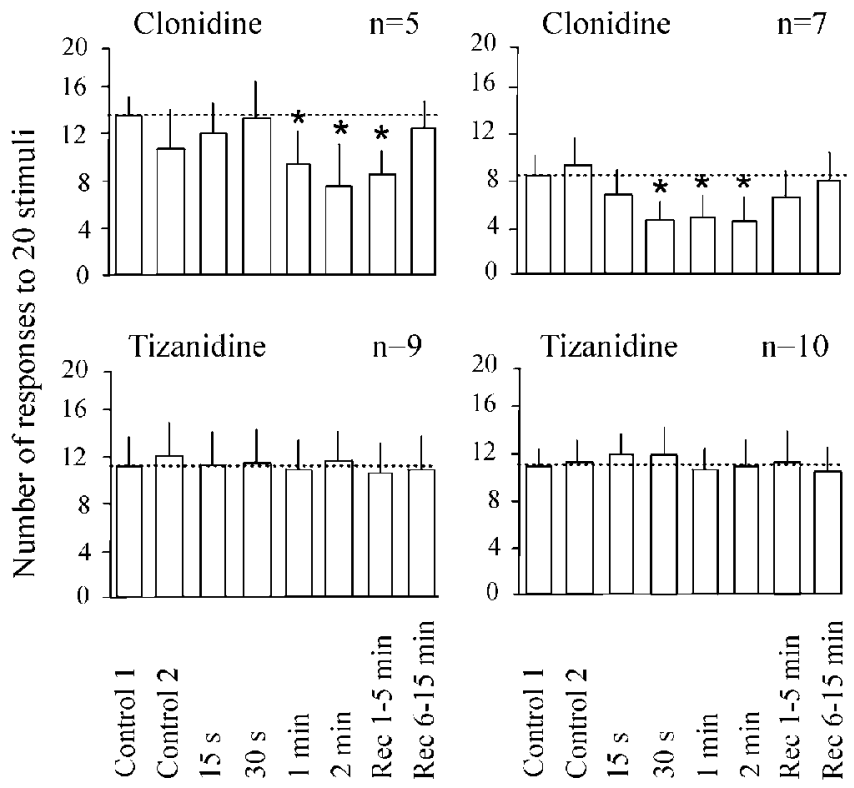

Figure 4. Comparison of effects of clonidine and tizanidine on samples of la and la/lb interneurons. The effects of the two agonists are indicated by changes in the number of responses evoked by 20 consecutive stimuli (single or the first of two stimuli). The ordinate mean number of responses with SEM is shown. Control 1, Responses evoked before placement of the drugcontaining microelectrode. Control 2, Responses evoked after placement of the drug-containing microelectrode. 0ther data are for the time periods indicated below the bars during ionophoresis and during periods of $1-5$ and $6-15$ min of recovery after the end of ionophoresis. Statistically significant changes with respect to the first control data are indicated by an asterisk ( $p<$ 0.05). Dotted lines indicate mean number of responses in control 1.

0.05 ) for Ia and Ia/Ib interneurons, respectively]. The latencies were affected less clearly, with occasional records showing latencies shorter than control responses (by $\leq 0.16 \mathrm{msec}$ ); however, for the sample as a whole there was no statistically significant effect. The facilitation is exemplified in Figure 5 and summarized in Figure 7.

Isoproterenol

The modulatory effects of the $\beta$-receptor agonist isoproterenol were found to be facilitatory on both Ia interneurons $(n=5)$ and $\mathrm{Ia} / \mathrm{Ib}$ interneurons $(n=6)$, although the effect was much weaker than that of phenylephrine. In some cells, the modulatory effect was reflected in the changes in the slope of the histograms, as in Figure 6, rather than in the number of responses. When the number of responses was compared, as in Figure 7, the facilitation was not seen until after at least $1 \mathrm{~min}$ of ionophoresis and was only moderate after $2.5 \mathrm{~min}$ for Ia interneurons, with the mean number of responses increased from $12.8 \pm 1.2$ to $14.5 \pm 0.8(p<$ $0.05)$. It was not statistically significant for Ia/Ib interneurons (responses increased from $10.3 \pm 3$. to $12.5 \pm 2$ ). The latencies were not changed consistently, although in some neurons they were sometimes shortened. Examples of the strongest facilitatory actions of isoproterenol are shown in Figure 6.

\section{Discussion}

Differential modulation of responses evoked by NA agonists Although previous studies did not reveal any modulatory actions of monoamines on transmission from group I afferents (Lundberg, 1965; Anden et al., 1966; Jordan et al., 1977; Bras et al., 1989), it has been demonstrated recently that activation of some neurons by group I afferents is facilitated by monoamines. The 


\section{Ia interneuron}

Q 1.1T
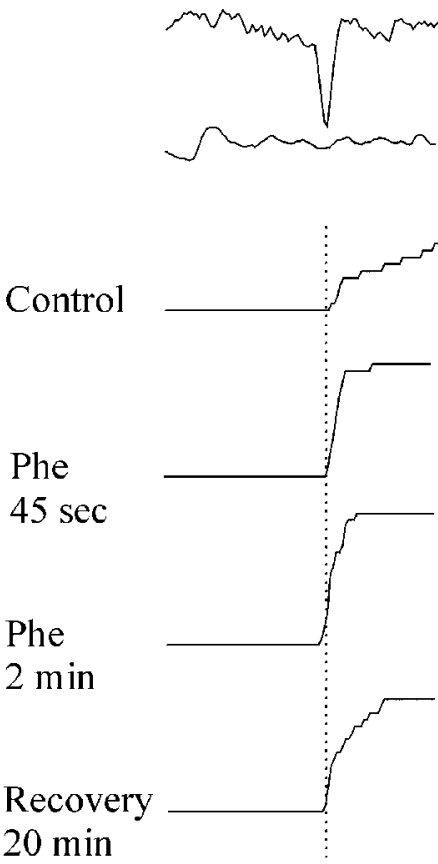
$20 \mathrm{~min}$
$\mathrm{Ia} / \mathrm{Ib}$ interneuron

GS $1.25 T$
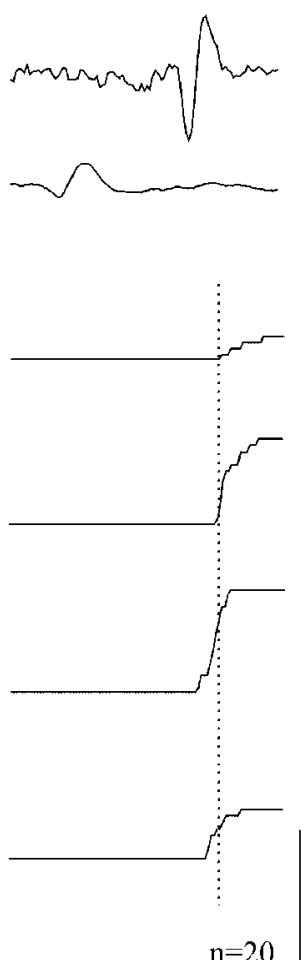

$\mathrm{n}=20$
Figure 5. Examples of facilitation of responses of an la interneuron and an la/lb interneuron by phenylephrine (Phe). Top records show responses of the neurons aligned with records of afferent volleys and with cumulative sums of these responses before, during, and after ionophoresis, as in Figure 3. Note the marked increase in the number of responses during ionophoresis and shorter latencies. Dotted lines indicate mimimal latencies in control records.

investigated neurons included neurons of origin of the VSCTs (Jankowska et al., 1998; Hammar et al., 2002) and the two populations of inhibitory interneurons (Jankowska et al., 2000) further investigated in the present study, interneurons mediating reciprocal inhibition of motoneurons from group Ia afferents, and interneurons mediating nonreciprocal inhibition from group Ia and Ib afferents. The results reported in this study show that the previously described facilitatory actions of NA on these neurons are reproduced by ionophoretic application of the $\alpha 1$ receptor agonist phenylephrine and, although to a lesser degree, by the $\beta$-receptor agonist isoproterenol, but not by the $\alpha 2$ receptor agonists clonidine and tizanidine. Clonidine, instead, has been found to depress activation of these interneurons (i.e., to have an effect opposite of that of NA), and tizanidine has been found to lack any effect. The results, summarized in Figures 4 and 7 , indicate that, despite some differences in the kinetics of the effects (the time to onset and the duration), interneurons of the two populations behave in a similar way after application of each of the tested agonists. This might indicate a similar expression and distribution of the involved receptor subtypes on presynaptic group I afferent terminals and/or on the postsynaptic interneuronal membrane.

The facilitatory effects of phenylephrine were found to be stronger than the effects of isoproterenol on Ia- and Ia/Ibinhibitory interneurons (this study) as well as on VSCT neurons (Hammar et al., 2002), indicating a particularly important role of
Ia interneuron

Q 1.1T
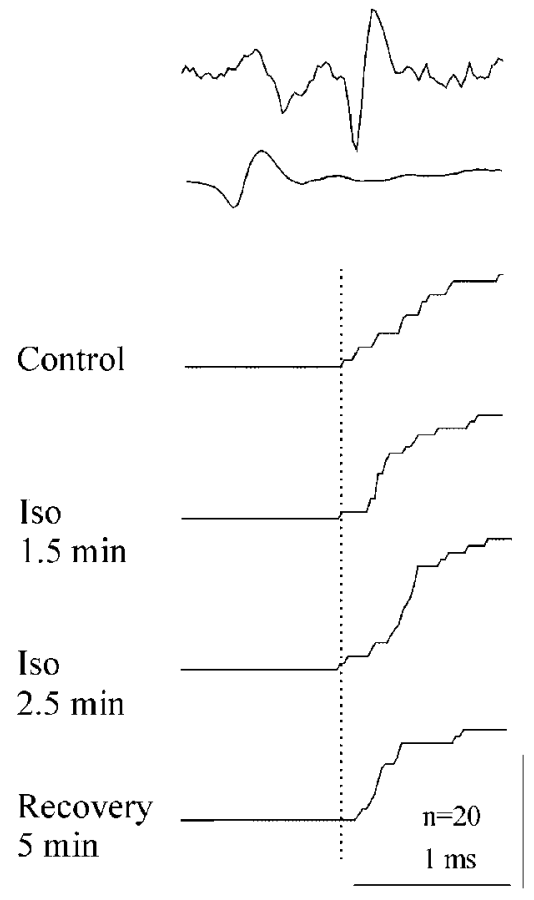

Figure 6. Examples of facilitation of responses of an la interneuron and an la/lb interneuron by isoproterenol (/so). Top records show responses of the neurons aligned with simultaneously recorded afferent volleys and cumulative sums of these responses, as in Figure 3. Dotted lines indicate mimimal latencies in control records.

$\alpha 1$-subclass membrane receptors in these modulatory actions. Because $\alpha 1$-subtype membrane receptors are reported to be located primarily postsynaptically on neurons and to act by decreasing potassium conductance (Nicoll et al., 1990), and because there is as yet no information on the expression of $\alpha 1$-subtype membrane receptors on terminals of primary afferents, these effects are most likely mediated by the activation of postsynaptic membrane receptors on the neurons. Postsynaptic noradrenergic contacts have been identified on VSCT neurons with monosynaptic group I input (Hammar and Maxwell, 2002), and there also are strong indications for such contacts on Ia and Ia/Ib interneurons (Maxwell et al., 2000). Of the two $\alpha 2$-receptor agonists, which failed to reproduce the previously observed effects of NA, clonidine has been found to depress activation of both VSCT neurons (Hammar and Maxwell, 2002) and interneurons investigated in this study. Studies on the distribution of $\alpha 2$ receptors in the spinal cord are still at a very preliminary stage. However, $\alpha 2$ receptors have been found on some spinal neurons (Rosin et al., 1996; Shi et al., 1999) and on some primary afferent terminals containing substance P (Stone et al., 1998) in the rat, and although no NA-containing axons have been found to form axoaxonic contacts with terminals of primary afferents in the feline spinal cord (Maxwell and Bannatyne, 1983; Doyle and Maxwell, 1991), they could be activated by volume conductance (Agnati and Fuxe, 2000). The depressive actions of clonidine might be mediated, therefore, by actions on primary afferents as well as on neurons contacted by them, and the resulting depression may reflect the sum of the modulatory actions at both of these locations.

The differences in the effects of the two tested $\alpha 2$-receptor 
la interneurons

$\mathrm{Ia} / \mathrm{Ib}$ interneurons
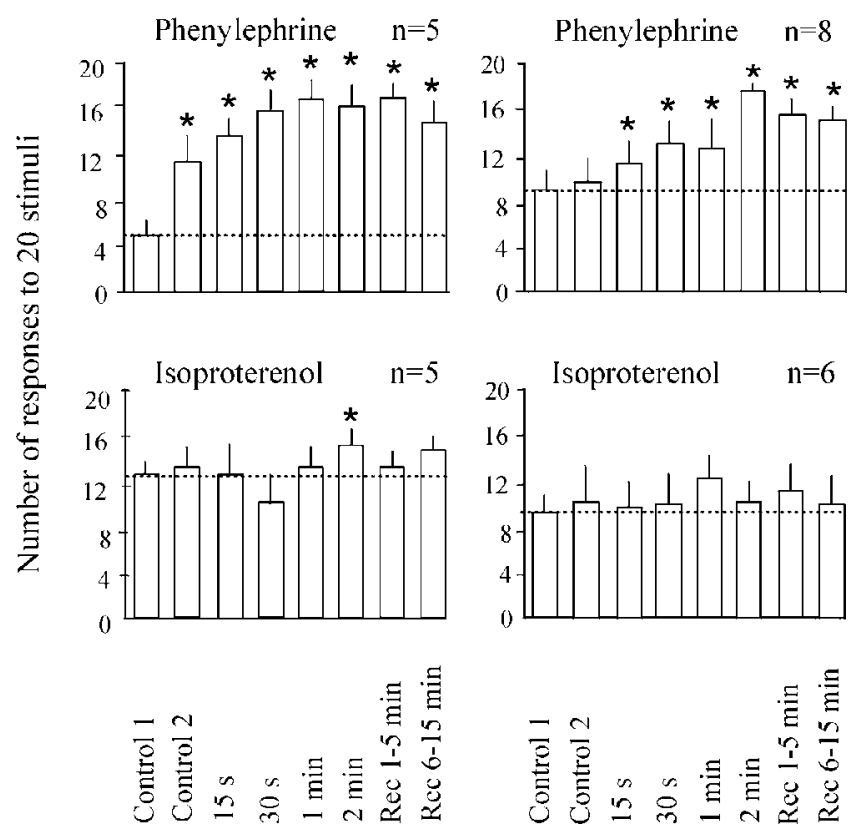

Figure 7. Comparison of effects of phenylephrine and isoproterenol on samples of la and $\mathrm{la} / \mathrm{lb}$ interneurons. The effects of the agonists are indicated by changes in the number of responses evoked by 20 consecutive stimuli, as in Figure 4. Ordinate mean number of responses with SEM. Statistically significant changes with respect to the first control data are indicated by an asterisk $(p<0.05)$. Dotted lines indicate mean number of responses in control 1.

agonists, clonidine and tizanidine, on interneurons investigated in the present study and on VSCT neurons so far cannot be explained, because this would require a better knowledge of the mode of actions of these drugs on spinal neurons. However, because both of these agonists may act on $\alpha 1$ - as well as on $\alpha 2$ membrane receptors (Coward, 1994), their effects may depend on the degree of activation of $\alpha 1$ - and $\alpha 2$-membrane receptors on the various neurons and on the summation of activation of these receptors.

\section{Functional considerations}

Deficits in the monoaminergic modulation of transmission from primary afferents to motoneurons and interneurons in the spinal cord may be one of the mechanisms behind pathological changes in motor performance after injuries to the CNS, in the case of spasticity in particular. Hyperexcitability of $\alpha$-motoneurons associated with exaggerated stretch and flexion reflexes in spastic patients may be caused by several factors. Strong evidence has been provided that these factors involve pathological changes at the level of $\alpha$-motoneurons themselves, including observations that bistability and plateau potentials in $\alpha$-motoneurons accompany hyperreflexia after spinal injuries in cats and rats (Hultborn and Malmsten, 1983a,b; Eken and Kiehn, 1989; Taylor et al., 1997; Bennett et al., 2001a,b). Strong evidence also has been provided for the involvement of pathological changes at a premotoneuronal level. After electrical stimulation of group II afferents in muscle nerves, oligosynaptically evoked excitation of motoneurons has been shown to be enhanced considerably in spastic patients in which monosynaptic reflexes from group Ia afferents (H-reflexes) were not changed (Marque et al., 2001). Weakening of presynaptic inhibition of transmission from group I afferents was observed less consistently (Faist et al., 1994; Aymard et al., 2000), and postsynaptic inhibition from group I afferents was found to be not only depressed (Nakashima et al., 1989; Delwaide, 1993; Crone et al., 1994; Delwaide and Pennisi, 1994) but also enhanced (Yanagisawa and Tanaka, 1978; Boorman et al., 1991). One of the means to estimate the relative contribution of these factors to the development of spasticity might be to compare the effects of the compounds that reduce spasticity on motoneurons and on interneurons in various reflex pathways to motoneurons. Such a comparison shows that antispastic noradrenergic drugs, e.g., clonidine (Nance et al., 1989; Coward, 1994), would enhance rather than weaken motoneuronal bistability (Conway et al., 1988) or would not have any effect on plateau potentials in chronically isolated spinal cord segments (D. J. Bennett, personal communication). These drugs also would weaken rather than enhance the inhibition of motoneurons by group I afferents (present study) and would not have any effect on the presynaptic inhibition of group I afferents (Anden et al., 1966). $\alpha 2$-Receptor agonists, therefore, could not be expected to counteract spasticity by acting directly on motoneurons or by modulating input from group I afferents to these neurons. The depressive effects of NA, clonidine, and tizanidine on interneurons in excitatory pathways between group II muscle afferents and motoneurons (Bras et al., 1990; Jankowska et al., 2000; Jankowska and Hammar, 2002) are, on the contrary, fully in keeping with the postulated antispastic effects of $\alpha 2$-receptor agonists related to the depression of activation of these interneurons and of their actions on motoneurons. It has been proposed, therefore, that the lack of inhibitory control of interneurons in excitatory pathways between group II muscle afferents and motoneurons by descending monoaminergic pathways is one of the main causes of hyperexcitability of motoneurons associated with spasticity at a premotoneuronal level (Jankowska, 1993; Eriksson et al., 1996; Jankowska and Hammar, 2002). The results of the present study, therefore, are in full support of this proposal.

\section{References}

Agnati LF, Fuxe K (2000) Volume transmission as a key feature of information handling in the central nervous system: possible new interpretative value of the Turing's B-type machine. Prog Brain Res 125:3-19.

Anden NE, Jukes MG, Lundberg A, Vyklicky L (1966) The effect of DOPA on the spinal cord. I. Influence on transmission from primary afferents. Acta Physiol Scand 67:373-386.

Aymard C, Katz R, Lafitte C, Lo E, Penicaud A, Pradat-Diehl P, Raoul S (2000) Presynaptic inhibition and homosynaptic depression: a comparison between lower and upper limbs in normal human subjects and patients with hemiplegia. Brain 123:1688-1702.

Bennett DJ, Li Y, Siu M (2001a) Plateau potentials in sacrocaudal motoneurons of chronic spinal rats, recorded in vitro. J Neurophysiol 86:1955-1971.

Bennett DJ, Li YL, Harvey PJ, Gorassini M (2001b) Evidence for plateau potentials in tail motoneurons of awake chronic spinal rats with spasticity. J Neurophysiol 86:1972-1982.

Boorman G, Hulliger M, Lee RG, Tako K, Tanaka R (1991) Reciprocal Ia inhibition in patients with spinal spasticity. Neurosci Lett 127:57-60.

Bras H, Cavallari P, Jankowska E, McCrea D (1989) Comparison of effects of monoamines on transmission in spinal pathways from group I and II muscle afferents in the cat. Exp Brain Res 76:27-37.

Bras H, Jankowska E, Noga B, Skoog B (1990) Comparison of effects of various types of NA and 5-HT agonists on transmission from group II muscle afferents in the cat. Eur J Neurosci 2:1029-1039.

Conway BA, Hultborn H, Kiehn O, Mintz I (1988) Plateau potentials in alpha-motoneurones induced by intravenous injection of L-dopa and clonidine in the spinal cat. J Physiol (Lond) 405:369-384.

Coward DM (1994) Tizanidine: neuropharmacology and mechanism of action. Neurology 44:S6-10.

Crone C, Nielsen J, Petersen N, Ballegaard M, Hultborn H (1994) Disynaptic reciprocal inhibition of ankle extensors in spastic patients. Brain 117:1161-1168. 
Delwaide PJ (1993) Pathophysiological mechanisms of spasticity at the spinal cord level. In: Spasticity: mechanisms and management (Thilmann AF, Burke D, Rymer Z, eds), pp 296-308. Heidelberg: Springer.

Delwaide PJ, Pennisi G (1994) Tizanidine and electrophysiologic analysis of spinal control mechanisms in humans with spasticity. Neurology 44 [Suppl 9]:S21-S27.

Doyle CA, Maxwell DJ (1991) Catecholaminergic innervation of the spinal dorsal horn: a correlated light and electron microscopic analysis of tyrosine hydroxylase-immunoreactive fibres in the cat. Neuroscience 45:161-176.

Eken T, Kiehn O (1989) Bistable firing properties of soleus motor units in unrestrained rats. Acta Physiol Scand 136:383-394.

Engberg I, Källström Y, Marshall KC (1972) Double micromanipulator for independent impalements of one neurone with two electrodes. Acta Physiol Scand 84:4A.

Eriksson J, Olausson B, Jankowska E (1996) Antispastic effects of L-DOPA. Exp Brain Res 111:296-304.

Faist M, Mazevet D, Dietz V, Pierrot Deseilligny E (1994) A quantitative assessment of presynaptic inhibition of Ia afferents in spastics. Differences in hemiplegics and paraplegics. Brain 117:1449-1455.

Fern R, Harrison PJ, Riddell JS (1988) The ascending projection of interneurones activated by group I muscle afferent fibres of the cat hindlimb. J Physiol (Lond) 405:275-288.

Hammar I, Maxwell DJ (2002) Serotoninergic and noradrenergic axons make contacts with neurons of the ventral spinocerebellar tract in the cat. J Comp Neurol 443:310-319.

Hammar I, Chojnicka B, Jankowska E (2002) Modulation of responses of feline ventral spinocerebellar tract neurons by monoamines. J Comp Neurol 443:298-309.

Hongo T, Jankowska E, Lundberg A (1972) The rubrospinal tract. IV. Effects on interneurones. Exp Brain Res 15:54-78.

Hongo T, Jankowska E, Ohno T, Sasaki S, Yamashita M, Yoshida K (1983) The same interneurones mediate inhibition of dorsal spinocerebellar tract cells and lumbar motoneurones in the cat. J Physiol (Lond) 342:161-180.

Hultborn H, Malmsten J (1983a) Changes in segmental reflexes following chronic spinal cord hemisection in the cat. I. Increased monosynaptic and polysynaptic ventral root discharges. Acta Physiol Scand 119:405-422.

Hultborn H, Malmsten J (1983b) Changes in segmental reflexes following chronic spinal cord hemisection in the cat. II. Conditioned monosynaptic test reflexes. Acta Physiol Scand 119:423-433.

Hultborn H, Jankowska E, Lindstrom S (1971a) Recurrent inhibition of interneurones monosynaptically activated from group Ia afferents. J Physiol (Lond) 215:613-636.

Hultborn H, Jankowska E, Lindstrom S (1971b) Relative contribution from different nerves to recurrent depression of Ia IPSPs in motoneurones. J Physiol (Lond) 215:637-664.

Jack JJB (1978) Some methods for selective activation of muscle afferent fibres. In: Studies in neurophysiology (Porter R, ed), pp 155-176. Cambridge, UK: Cambridge UP.

Jankowska E (1993) Monoaminergic inhibitory control of spinal interneurons. In: Spasticity: mechanisms and management (Thilmann AF, Burke D, Rymer Z, eds), pp 222-232. Berlin: Springer.

Jankowska E, Hammar I (2002) Spinal interneurons: how can studies in animals contribute to the understanding of spinal interneuronal systems in man? Brain Res Brain Res Rev, in press.

Jankowska E, Roberts W (1972) Synaptic actions of single interneurones mediating reciprocal Ia inhibition of motoneurones. J Physiol (Lond) 222:623-642.
Jankowska E, Hammar I, Djouhri L, Heden C, Szabo Lackberg Z, Yin XK (1997) Modulation of responses of four types of feline ascending tract neurons by serotonin and noradrenaline. Eur J Neurosci 9:1375-1387.

Jankowska E, Simonsberg IH, Chojnicka B (1998) Modulation of information forwarded to feline cerebellum by monoamines. Ann NY Acad Sci 860:106-109.

Jankowska E, Hammar I, Chojnicka B, Heden CH (2000) Effects of monoamines on interneurons in four spinal reflex pathways from group I and/or group II muscle afferents. Eur J Neurosci 12:701-714.

Jordan LM, McCrea DA, Steeves JD, Menzies JE (1977) Noradrenergic synapses and effects of noradrenaline on interneurons in the ventral horn of the cat spinal cord. Can J Physiol Pharmacol 55:399-412.

Lundberg A (1965) Monoamines and spinal cord. In: Studies in physiology, (Curtis DR, McIntyre AK, eds) pp 186-190. Heidelberg: Springer.

Marque P, Simonetta-Moreau M, Maupas E, Roques CF (2001) Facilitation of transmission in heteronymous group II pathways in spastic hemiplegic patients. J Neurol Neurosurg Psychiatry 70:36-42.

Maxwell DJ, Bannatyne BA (1983) Ultrastructure of muscle spindle afferent terminations in lamina VI of the cat spinal cord. Brain Res 288:297-301.

Maxwell DJ, Riddell JS, Jankowska E (2000) Serotoninergic and noradrenergic axonal contacts associated with premotor interneurons in spinal pathways from group II muscle afferents. Eur J Neurosci 12:1271-1280.

Mazzocchio R, Rossi A (1997) Involvement of spinal recurrent inhibition in spasticity. Further insight into the regulation of Renshaw cell activity. Brain 120:991-1003.

McCrea DA (1998) Neuronal basis of afferent-evoked enhancement of locomotor activity. Ann NY Acad Sci 860:216-225.

Morita H, Crone C, Christenhuis D, Petersen NT, Nielsen JB (2001) Modulation of presynaptic inhibition and disynaptic reciprocal Ia inhibition during voluntary movement in spasticity. Brain 124:826-837.

Nakashima K, Rothwell JC, Day BL, Thompson PD, Shannon K, Marsden CD (1989) Reciprocal inhibition between forearm muscles in patients with writer's cramp and other occupational cramps, symptomatic hemidystonia and hemiparesis due to stroke. Brain 112:681-697.

Nance PW, Shears AH, Nance DM (1989) Reflex changes induced by clonidine in spinal cord injured patients. Paraplegia 27:296-301.

Nicoll RA, Malenka RC, Kauer JA (1990) Functional comparison of neurotransmitter receptor subtypes in mammalian central nervous system. Physiol Rev 70:513-565.

Pierrot Deseilligny E (1990) Electrophysiological assessment of the spinal mechanisms underlying spasticity. Electroencephalogr Clin Neurophysiol Suppl 41:264-273.

Rosin DL, Talley EM, Lee A, Stornetta RL, Gaylinn BD, Guyenet PG, Lynch KR (1996) Distribution of alpha 2C-adrenergic receptor-like immunoreactivity in the rat central nervous system. J Comp Neurol 372:135-165.

Rudomin P, Schmidt RF (1999) Presynaptic inhibition in the vertebrate spinal cord revisited. Exp Brain Res 129:1-37.

Shi TJ, Winzer-Serhan U, Leslie F, Hokfelt T (1999) Distribution of alpha2adrenoceptor mRNAs in the rat lumbar spinal cord in normal and axotomized rats. NeuroReport 10:2835-2839.

Stone LS, Broberger C, Vulchanova L, Wilcox GL, Hokfelt T, Riedl MS, Elde R (1998) Differential distribution of $\alpha 2 \mathrm{~A}$ and $\alpha 2 \mathrm{C}$ adrenergic receptor immunoreactivity in the rat spinal cord. J Neurosci 18:5928-5937.

Taylor JS, Friedman RF, Munson JB, Vierck Jr CJ (1997) Stretch hyperreflexia of triceps surae muscles in the conscious cat after dorsolateral spinal lesions. J Neurosci 17:5004-5015.

Yanagisawa N, Tanaka R (1978) Reciprocal Ia inhibition in spastic paralysis in man. Electroencephalogr Clin Neurophysiol Suppl 34:521-526. 